\title{
Feijão guandu cru na alimentação de frangos caipiras criados em sistema semi-intensivo
}

\author{
Dalila Polyana Alencar(1), Mônica Patrícia Maciel(1), Luiz Fernando Rocha Botelho(1), Luciana Albuquerque

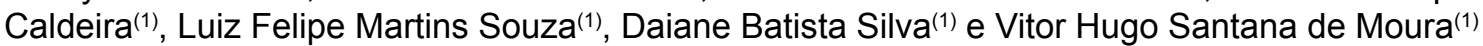

\begin{abstract}
(1)Universidade Estadual de Montes Claros, Departamento de Ciências Agrárias, Avenida Reinaldo Viana, no 2.630, Bico da Pedra, CEP 39440-000 Janaúba, MG, Brasil. E-mail: dalipoly@yahoo.com.br, monicapmaciel@hotmail.com, luiz.fernando1989@zootecnista.com.br, luburq@yahoo.com.br, luiz_felipe01@hotmail.com, daianebatistas88@yahoo.com.br, santmoura@yahoo.com.br
\end{abstract}

\begin{abstract}
Resumo - O objetivo deste trabalho foi avaliar os efeitos da substituição do farelo de soja pelo feijão guandu cru na alimentação de frangos caipiras criados em sistema semi-intensivo. Foram utilizados 525 frangos de corte da linhagem Caipira Pesadão, com idade inicial de 35 dias, distribuídos em cinco tratamentos com cinco repetições de 21 aves cada um. Os tratamentos consistiram na substituição de $0,5,10,15$ e $20 \%$ do farelo de soja pelo feijão guandu cru moído. Foram avaliados o ganho de peso, o consumo de ração, a conversão alimentar, o rendimento de carcaça e de cortes, o peso do pâncreas e a qualidade da carne. A substituição do farelo de soja pelo feijão guandu em até $15,45 \%$, nas dietas de frangos caipiras de corte, com idade de 57 a 71 dias, não altera o ganho de peso. $\mathrm{O}$ aumento dos níveis de feijão guandu na ração não afeta o rendimento de carcaça, o peso do pâncreas e os parâmetros de qualidade da carne.
\end{abstract}

Termos para indexação: Cajanus cajan, alimento alternativo, aves caipiras, desempenho, rendimento de carcaça.

\section{Raw pigeon pea in the diet of free-range broilers reared in a semi-intensive system}

\begin{abstract}
The objective of this work was to evaluate the effects of replacing soybean meal by raw pigeon pea in the diet of free-range broilers reared in a semi-intensive system. Five hundred twenty-five broilers of the Caipira Pesadão lineage were used, with initial age of 35 days, distributed in five treatments with five replicates of 21 birds each. Treatments consisted of the replacement of $0,5,10,15$, and $20 \%$ of soybean meal by ground raw pigeon pea. Weight gain, feed intake, feed conversion, carcass and cuts yield, pancreas weight, and meat quality were evaluated. Replacing soybean meal by pigeon pea in up to $15.45 \%$ in the diet of free-range meat broilers, with age of 57 to 71 days, does not change weight gain. Increasing levels of pigeon pea in the diet do not affect carcass yield, pancreas weight, and meat quality parameters.
\end{abstract}

Index terms: Cajanus cajan, alternative feed, free-range birds, performance, carcass yield.

\section{Introdução}

A criação de aves para a produção de carne do tipo caipira, no sistema semi-intensivo, é um dos segmentos da avicultura que tem se mostrado promissor (Santos et al., 2005). A carne produzida apresenta sabor diferenciado, que agrada ao paladar de consumidores à procura de alimentos com maiores atributos de qualidade (Carrijo et al., 2010). No entanto, o desafio nesse tipo de criação é tornar a produção mais eficiente, ao diminuir os custos com a alimentação, sem perder as características dos produtos.

O aumento na demanda por fontes de proteína e o seu alto custo tem estimulado pesquisas que buscam novas alternativas para substituir as tradicionais fontes proteicas, principalmente a do farelo de soja. O feijão guandu [Cajanus cajan (L.) Millsp.] é uma dessas alternativas, pois apresenta boas quantidades de proteína bruta, que variam entre 22 e $27 \%$ (Onu \& Okongwu, 2006; Iorgyer et al., 2009; Amaefule et al., 2011). Além disso, é uma leguminosa resistente à seca, fator importante para sua cultura em regiões semiáridas (Vieira et al., 2001).

Entretanto, o feijão guandu, como outras leguminosas, apresenta fatores antinutricionais, como inibidores de proteases (tripsina e quimotripsina) e hemaglutininas, que podem diminuir a digestibilidade dos nutrientes, o que afeta o desempenho animal. 
Os efeitos dos inibidores de proteases em animais não ruminantes alimentados com leguminosas cruas geralmente são observados em alterações metabólicas do pâncreas, como o aumento da secreção enzimática, com consequente hipertrofia e hiperplasia do órgão (Brito et al., 2006; Leite et al., 2012). Para tentar amenizar esse problema, as sementes de feijão têm sido submetidas ao tratamento térmico, que, porém, encarece o custo das rações e, portanto, o custo final da produção de frangos (Hajos \& Osagie, 2004).

Onu \& Okongwu (2006), ao avaliar a inclusão de $26 \%$ de farelo da semente do feijão guandu cru ou processado (cozido ou tostado) na dieta de frangos de corte da linhagem Anak 2000, na fase inicial de 1 a 28 dias, constataram menor digestibilidade da proteína bruta e menor desempenho das aves. Já Amaefule et al. (2011), em pesquisa com frangos de corte da linhagem Marshal, também na fase inicial de criação, concluíram que o feijão guandu cru pode ser utilizado nas proporções de 30 e $40 \%$, desde que as rações sejam suplementadas com metionina e metionina+lisina, respectivamente. De acordo com estes autores, o menor desempenho observado nas aves que receberam a ração com guandu sem a suplementação pode ser atribuído à presença de fatores antinutricionais, especialmente o inibidor de tripsina.

Na literatura, ainda são escassos os dados referentes à utilização do feijão guandu cru na dieta de frangos caipiras. Essas aves apresentam crescimento lento e respostas diferenciadas em relação às das aves de crescimento rápido (Santos et al., 2005); assim, há a necessidade de pesquisas que apontem a viabilidade da utilização dessa fonte proteica alternativa, bem como a quantidade adequada para o bom desempenho das aves.

O objetivo deste trabalho foi avaliar os efeitos da substituição do farelo de soja pelo feijão guandu cru na alimentação de frangos caipiras criados em sistema semi-intensivo.

\section{Material e Métodos}

O experimento foi realizado entre maio e julho de 2011, na Fazenda Experimental da Universidade Estadual de Montes Claros, no Município de Janaúba, no norte do Estado de Minas Gerais $\left(15^{\circ} 47^{\prime} 50^{\prime \prime} \mathrm{S}\right.$, $43^{\circ} 18^{\prime} 31^{\prime \prime} \mathrm{W}$, a $516 \mathrm{~m}$ de altitude).
Inicialmente, um pré-ensaio de metabolismo foi realizado para determinar a energia metabolizável e a composição química do feijão guandu; os dados obtidos foram utilizados na formulação das rações experimentais. Foram utilizados 160 pintos fêmeas com 21 dias de idade, da linhagem Caipira Pesadão, alojados em 16 baterias metálicas, que mediam $0,50 \times 0,40 \times 0,75 \mathrm{~m}$ e estavam equipadas com bebedouro automático do tipo chupeta e com comedouro do tipo calha. Utilizouse o delineamento inteiramente casualizado, com dois tratamentos e oito repetições de dez aves cada um, o que totalizou 16 unidades experimentais. Os tratamentos consistiram de uma ração-referência (Tabela 1) e de uma ração-teste $(60 \%$ da ração-referência e $40 \%$ de feijão guandu cru moído). A ração-referência foi formulada para atender às exigências nutricionais de frangos de corte de desempenho médio, na fase de

Tabela 1. Composição centesimal da ração-referência utilizada para o ensaio de metabolismo, em frangos caipiras de corte da linhagem Caipira Pesadão.

\begin{tabular}{lc}
\hline Ingredientes & Quantidade (kg) \\
\hline Milho & 63,00 \\
Farelo de soja & 30,53 \\
Óleo de soja & 2,92 \\
Fosfato bicálcico & 1,55 \\
Calcário & 0,76 \\
Sal comum & 0,40 \\
Suplemento mineral vitamínico ${ }^{(1)}$ & 0,40 \\
DL-metionina & 0,21 \\
L-lisina & 0,18 \\
L-treonina & 0,03 \\
\hline Total & 100 \\
\hline Energia metabolizável aparente corrigida (kcal kg-1) & 3.125 \\
Proteína bruta (\%) & 19,62 \\
Lisina digestível (\%) & 1,15 \\
Metionina+cistina (\%) & 0,82 \\
Treonina (\%) & 0,78 \\
Cálcio (\%) & 0,79 \\
Fósforo disponível (\%) & 0,39 \\
Sódio (\%) & 0,19 \\
\hline (1)Composição por kg do produto: vitamina A, 2.500 UI; vitamina D3, \\
500.000 UI; vitamina E, 5.000 mg; vitamina B1, 500 mg; vitamina B2, \\
1.000 mg; vitamina B6, 1.000 mg; ácido pantotênico, 2.500 mg; biotina, \\
15 mg; vitamina K3, 500 mg; ácido fólico, 250 mg; niacina, 7.500 mg; \\
vitamina B12, 5.000 mg; vitamina C, 12.500 mg; colina,150.000 mg; an- \\
tioxidante, 24.000 mg; manganês, 19.500 mg; ferro, 12.55 mg; zinco, \\
13.750 mg; cobre, 2.500 mg; iodo, 175 mg; selênio, 45 mg; metionina, \\
375.000 mg. & \\
&
\end{tabular}


crescimento, conforme Rostagno (2005). No décimo oitavo dia de idade dos frangos, foi iniciado o período de adaptação à ração experimental, que durou quatro dias. No vigésimo primeiro dia, foi realizado jejum de 4 horas para permitir que o trato digestivo das aves fosse esvaziado e para demarcar o início do período de coleta. Cada bateria era provida de duas bandejas revestidas de plástico para que não houvesse perda de excretas. As excretas foram coletadas durante quatro dias, sendo que, no último dia, também foi realizado jejum de 4 horas para demarcar o fim do período de coleta. Ao término do pré-ensaio, foi determinada a quantidade de ração consumida e a quantidade excretada por unidade experimental durante os quatro dias de coleta. As excretas foram acondicionadas em sacos de plástico, identificadas por repetição e congeladas a $-4^{\circ} \mathrm{C}$. No final do período experimental, foram determinadas a quantidade de ração consumida e a quantidade total de excretas produzidas. Após o descongelamento em temperatura ambiente, as excretas foram homogeneizadas por repetição, tendose retirado amostra de $500 \mathrm{~g}$ que foi seca em estufa de ventilação forçada, a $55^{\circ} \mathrm{C}$, por 72 horas. Em seguida, as amostras foram moídas em micro moinho de facas do tipo Willey, modelo TE-648 (Tecnal Equipamentos para Laboratórios, Piracicaba, SP), com peneira de $1 \mathrm{~mm}$. Foram determinados matéria seca, energia bruta e N, conforme Silva \& Queiroz (2006).

Com base nos resultados obtidos, foram calculados os valores de energia metabolizável aparente (EMA) e aparente corrigida $\left(\mathrm{EMA}_{\mathrm{n}}\right)$, apresentados em kcal $\mathrm{kg}^{-1}$ de matéria seca das dietas, tendo-se utilizado as equações propostas por Matterson et al. (1965), e ajustados para a retenção de $\mathrm{N}$ de acordo com as fórmulas: $\mathrm{EMA}=$ energia bruta ingerida - energia bruta excretada/matéria seca ingerida; e $\mathrm{EMA}_{\mathrm{n}}=$ energia bruta ingerida - (energia bruta excretada $+8,22$ $\times \mathrm{BN}$ )/matéria seca ingerida, em que $\mathrm{BN}$ é o balanço de nitrogênio. Os valores obtidos para proteína bruta, extrato etéreo, fibra bruta, matéria seca, energia bruta e energia metabolizável aparente corrigida para retenção de nitrogênio foram: 25,03, 1,13, 5,95, 89,83, 3.823 e $1.795 \mathrm{kcal} \mathrm{kg}^{-1}$, respectivamente.

Após a realização do pré-ensaio, foi montado experimento com 525 frangos de corte fêmeas, da linhagem caipira melhorado Caipira Pesadão, a partir dos 35 dias de idade, com peso médio inicial de $700 \mathrm{~g}$. As aves foram alojadas em piquetes com livre acesso diário ao capim Tifton 85 (Cynodon dactylon) e foram confinadas somente à noite para evitar ataque de predadores. A densidade utilizada foi de uma ave a cada $3 \mathrm{~m}^{2}$ no piquete e de dez aves a cada $1 \mathrm{~m}^{2}$ no abrigo. As rações experimentais foram formuladas com base nas exigências para frangos de corte de desempenho médio, conforme Rostagno (2005), para a fase de crescimento ( 35 a 56 dias) e para a fase de terminação (57 a 71 dias), o que totalizou período experimental de 43 dias (Tabela 2). A ração e a água foram fornecidas à vontade, em piquete com comedouro tubular e dois bebedouros do tipo pressão - um ficava dentro do abrigo e outro no piquete. As aves foram distribuídas em delineamento inteiramente casualizado, com cinco tratamentos e cinco repetições de 21 aves cada um. Os tratamentos consistiram de diferentes níveis de substituição do farelo de soja pelo feijão guandu cru moído $(5,10,15$ e $20 \%)$ e do controle $(0 \%)$.

Para a obtenção do peso vivo, todas as aves foram pesadas semanalmente com uma balança portátil eletrônica, com precisão de $20 \mathrm{~g}$ (Walmur, Porto Alegre, RS). As aves foram mantidas em jejum por 4 horas para a realização das pesagens, com normalização do arraçoamento em seguida. Ao final da semana, as sobras das rações foram pesadas para a determinação do consumo de ração. A mortalidade foi registrada diariamente para que fosse possível realizar os ajustes dos cálculos referentes ao consumo de ração e à conversão alimentar (Sakomura \& Rostagno, 2007).

$\mathrm{O}$ rendimento de carcaça foi avaliado ao final do período experimental (71 dias de idade). Foram separadas 50 aves ao todo, duas por unidade experimental, de peso igual a $\pm 5 \%$ da média da parcela. As aves foram submetidas a jejum de 8 horas, para o esvaziamento do trato gastrointestinal, e sacrificadas por deslocamento cervical (protocolo $n^{\circ}$ 16/2011 da Comissão de Ética em Experimentação Animal da Universidade Estadual de Montes Claros). Posteriormente, foram submetidas à sangria, à escaldagem $\left(60^{\circ} \mathrm{C}\right.$ por $\left.120 \mathrm{~s}\right)$, à depena automática em depenadeira em aço inox, modelo AISI 304 (Top Inox, Cariacica, ES) e à evisceração manual. Em seguida, foi medido o $\mathrm{pH}$ inicial na região peitoral. As carcaças quentes foram pesadas e tiveram a gordura abdominal (gordura aderida à moela + abdominal) retirada e pesada. Depois dessas etapas, foram realizados os processos de: pré-resfriamento, temperatura da água controlada próxima a $20^{\circ} \mathrm{C}$ por $30 \mathrm{~min}$; e resfriamento, temperatura 
da água de 0 a $8^{\circ} \mathrm{C}$ por $15 \mathrm{~min}$. Após o resfriamento, as aves foram dependuradas por $5 \mathrm{~min}$ para gotejamento da água residual. Em seguida, foram feitos os cortes para a avaliação do rendimento de carcaça e das partes comerciais (peito, coxa, sobrecoxa, perna inteira, asa e dorso) e dos pés.

$\mathrm{O}$ rendimento de carcaça foi obtido pela relação entre o peso da carcaça fria (sem cabeça) e o peso em jejum. O rendimento de peito, coxa, sobrecoxa, coxa+sobrecoxa, asa e dorso foi obtido pela relação entre o peso dessas partes e o da carcaça fria. A proporção de gordura abdominal e pés foi obtida pela relação entre o peso desses componentes e o peso das aves em jejum. O peso do pâncreas foi obtido durante o abate das aves, quando se retirou o pâncreas de duas aves por unidade experimental, tendo-se executado a limpeza de tecidos aderentes e gordura periférica, com posterior pesagem em balança analítica, modelo AR5120 (Toledo do Brasil Indústria de Balanças Ltda., São Bernardo do Campo, SP). Após a avaliação de rendimento, os cortes de peito, coxa e sobrecoxa foram embalados em papel alumínio, devidamente identificados e congelados à aproximadamente $-18^{\circ} \mathrm{C}$, para as avaliações de $\mathrm{pH}$, textura e atividade de água da carne.

As avaliações foram realizadas no Laboratório de Tecnologia de Produtos de Origem Animal e Vegetal da Universidade Estadual de Montes Claros, MG. Para o início das análises, os cortes foram submetidos ao processo de descongelamento em refrigerador, a $\pm 4^{\circ} \mathrm{C}$, lado a lado, para evitar o empilhamento das peças, por um período de 36 horas (Ramos \& Gomide, 2009). Para a avaliação da textura, foi utilizada a força de cisalhamento aplicada sobre a carne, conforme

Tabela 2. Composição percentual e níveis nutricionais calculados das rações experimentais com diferentes níveis $(0,5,10$, 15 e 20\%) de feijão guandu (Cajanus cajan) cru moído, para a fase de crescimento e de terminação de frangos caipiras da linhagem Caipira Pesadão.

\begin{tabular}{|c|c|c|c|c|c|c|c|c|c|c|}
\hline \multirow[t]{2}{*}{ Ingredientes } & \multicolumn{5}{|c|}{ Fase de crescimento ( 35 a 56 dias) } & \multicolumn{5}{|c|}{ Fase de terminação (57 a 71 dias) } \\
\hline & 0 & 5 & 10 & 15 & 20 & 0 & 5 & 10 & 15 & 20 \\
\hline Milho & 71,437 & 67,622 & 63,947 & 60,272 & 56,597 & 72,661 & 68,651 & 64,895 & 61,145 & 57,389 \\
\hline Farelo de soja & 24,305 & 22,050 & 19,602 & 17,154 & 14,706 & 23,100 & 21,084 & 18,697 & 16,309 & 13,922 \\
\hline Feijão guandu & 0,000 & 5,000 & 10,000 & 15,000 & 20,000 & 0,000 & 5,000 & 10,000 & 15,000 & 20,000 \\
\hline Óleo de soja & 1,571 & 2,618 & 3,623 & 4,627 & 5,632 & 2,010 & 3,118 & 4,147 & 5,175 & 6,203 \\
\hline Fosfato bicálcico & 0,868 & 0,908 & 0,949 & 0,990 & 1,031 & 0,730 & 0,762 & 0,802 & 0,843 & 0,883 \\
\hline Calcário & 0,654 & 0,639 & 0,624 & 0,609 & 0,594 & 0,600 & 0,584 & 0,569 & 0,554 & 0,539 \\
\hline Sal comum & 0,371 & 0,377 & 0,384 & 0,391 & 0,398 & 0,365 & 0,366 & 0,373 & 0,379 & 0,386 \\
\hline Suplemento mineral vitamínico ${ }^{(1)}$ & 0,400 & 0,400 & 0,400 & 0,400 & 0,400 & 0,200 & 0,200 & 0,200 & 0,200 & 0,200 \\
\hline DL-metionina & 0,146 & 0,189 & 0,234 & 0,279 & 0,325 & 0,103 & 0,144 & 0,190 & 0,230 & 0,275 \\
\hline L-lisina & 0,195 & 0,141 & 0,125 & 0,109 & 0,092 & 0,210 & 0,074 & 0,055 & 0,037 & 0,019 \\
\hline L-treonina & 0,050 & 0,052 & 0,109 & 0,165 & 0,221 & 0,020 & 0,014 & 0,069 & 0,124 & 0,180 \\
\hline Total & 100 & 100 & 100 & 100 & 100 & 100 & 100 & 100 & 100 & 100 \\
\hline $\mathrm{EM}^{(2)}\left(\mathrm{kcal} \mathrm{kg}^{-1}\right)$ & 3.150 & 3.150 & 3.150 & 3.150 & 3.150 & 3.200 & 3.200 & 3.200 & 3.200 & 3.200 \\
\hline Proteína bruta (\%) & 17,500 & 17,500 & 17,500 & 17,500 & 17,500 & 17,022 & 17,028 & 17,047 & 17,062 & 17,080 \\
\hline Lisina digestível (\%) & 1,007 & 0,983 & 0,983 & 0,983 & 0,983 & 0,988 & 0,905 & 0,905 & 0,905 & 0,905 \\
\hline Metionina + cistina $(\%)$ & 0,718 & 0,718 & 0,718 & 0,718 & 0,718 & 0,664 & 0,664 & 0,665 & 0,661 & 0,661 \\
\hline Treonina $(\%)$ & 0,717 & 0,668 & 0,668 & 0,668 & 0,668 & 0,670 & 0,615 & 0,615 & 0,615 & 0,615 \\
\hline Cálcio (\%) & 0,566 & 0,566 & 0,566 & 0,566 & 0,566 & 0,507 & 0,506 & 0,506 & 0,506 & 0,506 \\
\hline Fósforo disponível (\%) & 0,264 & 0,264 & 0,264 & 0,264 & 0,264 & 0,237 & 0,236 & 0,264 & 0,235 & 0,235 \\
\hline Sódio (\%) & 0,185 & 0,185 & 0,185 & 0,185 & 0,185 & 0,182 & 0,180 & 0,180 & 0,180 & 0,180 \\
\hline
\end{tabular}

${ }^{(1)}$ Composição por kg do produto: vitamina A, $2.500 \mathrm{UI}$; vitamina D3, $500.000 \mathrm{UI}$; vitamina E, $5.000 \mathrm{mg}$; vitamina B1, $500 \mathrm{mg}$; vitamina B2, $1.000 \mathrm{mg}$; vitamina B6, $1.000 \mathrm{mg}$; ácido pantotênico, $2.500 \mathrm{mg}$; biotina, $15 \mathrm{mg}$; vitamina $\mathrm{K} 3$, $500 \mathrm{mg}$; ácido fólico, $250 \mathrm{mg}$; niacina, $7.500 \mathrm{mg}$; vitamina B12, $5.000 \mathrm{mg}$; vitamina C, $12.500 \mathrm{mg}$; colina, $150.000 \mathrm{mg}$; antioxidante, $24.000 \mathrm{mg}$; manganês, $19.500 \mathrm{mg}$; ferro, $12.525 \mathrm{mg}$; zinco, $13.750 \mathrm{mg}$; cobre, $2.500 \mathrm{mg}$; iodo, $175 \mathrm{mg}$; selênio, $45 \mathrm{mg}$; metionina, $375.000 \mathrm{mg} .{ }^{(2)} \mathrm{EM}$, energia metabolizável. 
metodologia recomendada por Ramos \& Gomide (2009). Foi realizada a desossa do peito e retirado um filé de cada animal que foi cozido em grelha comum do tipo grill, Multi Grill 2, (Britânia, Curitiba, PR) até atingir temperatura interna de $71^{\circ} \mathrm{C}$. Após a etapa de cozimento, foram retiradas cinco amostras retangulares de $1,9 \times 2,1 \mathrm{~cm}$ no sentido paralelo às fibras musculares, com auxílio de vazador metálico, de fabricação própria, que serviu como molde afiado, de forma que as amostras fossem sempre cisalhadas na posição perpendicular à lâmina do texturômetro. A força de cisalhamento da carne foi medida com texturômetro com sonda do tipo "knife blade", TA.XT Express, (Stable Micro Systems, Surrey, Reino Unido). Os parâmetros definidos para essa análise foram: velocidade de pré-teste e de ensaio de $3 \mathrm{~mm} \mathrm{~s}^{-1}$, velocidade de retorno de $3 \mathrm{~mm} \mathrm{~s}^{-1}$ e distância do ensaio de $60 \mathrm{~mm} \mathrm{~s}^{-1}$, tendo-se obtido força de cisalhamento mínima e média e pico da força máxima, em kg. O texturômetro trabalhou conectado ao computador, e os dados coletados foram processados e apresentados pelo programa Texture Expert for Windows 1.20. A leitura foi realizada ao se observar o pico da força máxima de cisalhamento. As determinações das atividades de água $\left(a_{w}\right)$ foram feitas de acordo com Sabadini et al. (2001), tendo-se usado o aparelho AquaLab, modelo Series 3TE (Decagon Devices, Pullman, WA, EUA). Para a análise de cada corte (coxa, sobrecoxa e peito), foram utilizadas amostras que pesavam aproximadamente $5 \mathrm{~g}$, sem osso e sem pele.

Os dados de desempenho, rendimento e peso do pâncreas foram submetidos à análise de variância, $\mathrm{e}$, quando $\mathrm{o}$ teste $\mathrm{F}$ foi significativo, realizou-se análise de regressão, a $5 \%$ de probabilidade. Os dados de $\mathrm{pH}$, textura e atividade de água $\left(\mathrm{a}_{\mathrm{w}}\right)$ foram submetidos à análise de variância, e, quando o teste $\mathrm{F}$ foi significativo, utilizou-se o teste de Scott \& Knott, a $5 \%$ de probabilidade. As análises foram realizadas pelo programa Sisvar (Ufla, Lavras, MG).

\section{Resultados e Discussão}

O ganho de peso, o consumo de ração e a conversão alimentar não diferiram entre os tratamentos avaliados no período de crescimento, o que mostrou que as aves nessa fase se adaptaram às dietas contendo feijão guandu cru (Tabela 3). Resultado semelhante foi obtido por Mizubuti et al. (1995), para consumo e ganho de peso de frangos de corte da linhagem Arbor Acres, de 1 a 45 dias de idade, alimentados com rações com cinco níveis de feijão guandu cru moído. Estes autores concluíram que há viabilidade na substituição de até $20 \%$ do farelo de soja pelo feijão guandu, sem prejuízo ao desempenho dos animais. Já Amaefule et al. (2011) verificaram maior ganho de peso em frangos de corte da linhagem Marshal, na fase inicial de 1 a 28 dias, com ração controle sem adição de feijão guandu, comparada a rações contendo 30 e $40 \%$ de feijão guandu cru. Entretanto, quando estes autores suplementaram as dietas com metionina (ração com $30 \%$ de guandu) e metionina e lisina (ração com $40 \%$ de guandu), o desempenho das aves foi semelhante ao das aves do tratamento controle.

No período de terminação (57 a 71 dias), houve diferença entre os tratamentos quanto ao ganho de peso e à conversão alimentar (Tabela 3). Era esperado que

Tabela 3. Desempenho de frangos caipiras de corte da linhagem Caipira Pesadão alimentados com diferentes níveis de feijão guandu (Cajanus cajan) cru moído (FGCM) nas dietas, nas fases de crescimento e terminação.

\begin{tabular}{|c|c|c|c|c|c|c|}
\hline \multirow{2}{*}{$\begin{array}{l}\text { Níveis de FGCM } \\
(\%)\end{array}$} & \multicolumn{3}{|c|}{ Fase de crescimento ( 35 a 56 dias) } & \multicolumn{3}{|c|}{ Fase de terminação (57 a 71 dias) } \\
\hline & $\begin{array}{l}\text { Ganho de } \\
\text { peso }(g)\end{array}$ & $\begin{array}{c}\text { Consumo } \\
\text { de ração }(\mathrm{g})\end{array}$ & $\begin{array}{l}\text { Conversão } \\
\text { alimentar }\end{array}$ & $\begin{array}{l}\text { Ganho de } \\
\text { peso }(g)^{(1)}\end{array}$ & $\begin{array}{c}\text { Consumo } \\
\text { de ração }(\mathrm{g})\end{array}$ & $\begin{array}{l}\text { Conversão } \\
\text { alimentar }^{(2)}\end{array}$ \\
\hline 0 & $1.064,60$ & $2.575,12$ & 2,42 & $1.630,20$ & $4.560,64$ & 2,80 \\
\hline 5 & $1.107,16$ & $2.626,08$ & 2,43 & $1.657,33$ & $4.662,64$ & 2,81 \\
\hline 10 & $1.155,90$ & $2.640,84$ & 2,29 & $1.751,13$ & $4.688,44$ & 2,68 \\
\hline 15 & $1.093,81$ & $2.418,75$ & 2,21 & $1.726,17$ & $4.393,98$ & 2,55 \\
\hline 20 & $1.170,22$ & $2.574,84$ & 2,20 & $1.727,93$ & $4.592,78$ & 2,66 \\
\hline $\mathrm{p}$ & 0,1120 & 0,0815 & 0,0548 & 0,0237 & 0,0955 & 0,0200 \\
\hline CV (\%) & 5,99 & 4,93 & 6,42 & 3,62 & 3,74 & 4,72 \\
\hline
\end{tabular}

${ }^{(1)}$ Efeito quadrático $\left(\hat{\mathrm{y}}=1621,479+14,9713 \mathrm{x}-0,4843 \mathrm{x}^{2} ; \mathrm{R}^{2}=0,84^{* *}\right) .{ }^{(2)}$ Efeito quadrático $\left(\hat{\mathrm{y}}=2,8382-0,0222 \mathrm{x}+0,0006 \mathrm{x}^{2} ; \mathrm{R}^{2}=0,70^{* *}\right) \mathrm{p}=0,002$. 
as aves na fase de terminação apresentassem resultados similares aos daquelas na fase de crescimento. O ganho de peso apresentou comportamento quadrático, com máximo valor de $1.737 \mathrm{~g}$, na utilização de $15,45 \%$ de feijão guandu na ração. A conversão alimentar também apresentou comportamento quadrático, com melhor valor, de 2,63, quando utilizado $18,5 \%$ de feijão guandu. É possível que, nessa fase, os fatores antinutricionais contidos no feijão guandu cru tenham afetado o aproveitamento dos nutrientes pelas aves. Como não há conhecimento de trabalhos com a utilização de leguminosas cruas para frangos caipiras, sugere-se que essas aves apresentam respostas mais tardias aos fatores antinutricionais, quando comparadas aos frangos de corte comerciais.

Para os frangos de corte, alguns autores observaram efeitos negativos com níveis mais baixos de guandu. Ahmed et al. (2006) constataram que a substituição da fonte proteica da ração (farelo de gergelim) por apenas $10 \%$ de feijão guandu já prejudicou o consumo de ração, o ganho de peso e a conversão alimentar de frangos de corte da linhagem Lohman, de 1 a 42 dias de idade. Saeed \& Abdel Ati (2007) obtiveram menor ganho de peso e maior conversão alimentar ao utilizar apenas $5 \%$ de feijão guandu na dieta de frangos da linhagem Ross, de 1 a 42 dias de idade. Esses resultados são indicativos do baixo desempenho frente à presença de fatores antinutricionais, como inibidores de proteases e tripsina, no feijão guandu, o que pode influenciar negativamente a digestibilidade da proteína da dieta e, consequentemente, o ganho de peso e a conversão alimentar.

Vale ressaltar que, apesar dos efeitos negativos dos níveis mais altos de guandu sobre o ganho de peso e a conversão alimentar, os valores encontrados ainda estão próximos dos observados em experimentos com aves caipiras para corte (Santos et al., 2005; Madeira et al., 2010).

Não houve diferença no rendimento de carcaça e de cortes, na percentagem de gordura abdominal e no peso do pâncreas (Tabela 4). Resultados semelhantes foram relatados por Campello et al. (2009), que avaliaram a substituição do farelo de soja por soja crua, em rações para frangos de corte da linhagem Ross, de 22 a 42 dias de idade, e não observaram efeito deletério na carcaça e nos cortes.

A utilização do feijão guandu em até $20 \%$ não influenciou o peso do pâncreas, o que mostrou adaptação das aves à ração com a leguminosa crua. Já Campello et al. (2009) verificaram aumento do pâncreas em frangos de corte, dos 22 aos 42 dias de idade, que receberam rações com soja crua a partir do nível de $10,58 \%$, o que confirma as informações da literatura consultada de que o pâncreas é o órgão mais afetado pelos principais fatores antinutricionais contidos em leguminosas (Brito et al., 2006; Leite et al., 2012). As aves utilizadas no presente trabalho apresentam características genéticas diferentes das dos frangos de corte, de crescimento rápido; portanto, as respostas também diferem em relação à tolerância aos

Tabela 4. Rendimento de carcaça e cortes, gordura abdominal e peso do pâncreas de frangos caipiras da linhagem Caipira Pesadão, aos 71 dias de idade, alimentados com diferentes níveis de feijão guandu (Cajanus cajan) cru moído nas dietas avaliadas.

\begin{tabular}{|c|c|c|c|c|c|c|c|}
\hline \multirow[t]{2}{*}{ Variável } & \multicolumn{5}{|c|}{ Níveis de feijão guandu cru moído (\%) } & \multirow{2}{*}{$\begin{array}{l}\mathrm{CV} \\
(\%)\end{array}$} & \multirow[t]{2}{*}{$\mathrm{p}$} \\
\hline & 0 & 5 & 10 & 15 & 20 & & \\
\hline Rendimento de carcaça (\%) & 78,80 & 77,00 & 75,40 & 74,00 & 77,40 & 4,46 & 0,4404 \\
\hline Rendimento de peito $(\%)$ & 27,20 & 29,00 & 29,00 & 27,20 & 27,80 & 4,94 & 0,0840 \\
\hline Rendimento de coxa (\%) & 12,80 & 12,20 & 12,60 & 12,80 & 12,80 & 5,12 & 0,6522 \\
\hline Rendimento de sobrecoxa (\%) & 14,20 & 13,80 & 13,40 & 13,80 & 13,60 & 6,25 & 0,4554 \\
\hline Rendimento de perna inteira (\%) & 30,80 & 29,20 & 29,80 & 30,20 & 30,00 & 3,74 & 0,4362 \\
\hline Rendimento de dorso (\%) & 23,00 & 23,60 & 23,60 & 23,40 & 25,40 & 8,12 & 0,4094 \\
\hline Rendimento de asa (\%) & 5,18 & 5,00 & 5,10 & 5,26 & 5,14 & 5,31 & 0,6521 \\
\hline Rendimento de coxinha da asa (\%) & 5,82 & 5,58 & 5,76 & 5,90 & 5,88 & 4,39 & 0,3129 \\
\hline Rendimento de pé (\%) & 3,86 & 3,44 & 3,68 & 3,86 & 3,74 & 6,52 & 0,0718 \\
\hline Rendimento de pescoço (\%) & 7,00 & 6,40 & 6,40 & 6,60 & 7,20 & 12,62 & 0,4113 \\
\hline Gordura abdominal (\%) & 3,66 & 3,33 & 3,56 & 3,31 & 4,04 & 15,13 & 0,9223 \\
\hline Peso do pâncreas (g) & 4,80 & 5,07 & 5,03 & 4,93 & 5,15 & 11,84 & 0,8985 \\
\hline Peso relativo ( $\mathrm{g} \mathrm{kg}^{-1}$ de peso vivo) & 1,96 & 1,91 & 1,91 & 1,97 & 2,00 & 12,73 & 0,8823 \\
\hline
\end{tabular}


fatores antinutricionais contidos no feijão guandu cru. Outro fator importante a ser considerado é a idade em que as aves começaram a receber as rações; no caso do presente trabalho, a partir dos 35 dias. Aves mais jovens apresentam menor tolerância a esses fatores, como já observado em experimentos com frangos de corte (Brito et al., 2006; Amaefule et al., 2011). Os diferentes níveis de substituição do farelo de soja pelo feijão guandu cru não influenciaram os parâmetros de qualidade da carne (Tabela 5). Além da genética e do sexo, a nutrição influi no rendimento e na qualidade da carne de frangos de corte, principalmente quanto aos tipos de ingredientes utilizados na fabricação das rações e aos níveis de energia, proteína e aminoácidos da dieta (Rodrigues et al., 2008). Assim, ao se avaliar um novo alimento em dietas para animais, é imprescindível a análise dos parâmetros de qualidade da carne. No presente trabalho, o feijão guandu, nos níveis utilizados, é um alimento que não interfere na qualidade da carne.

Tabela 5. Atividade de água $\left(\mathrm{a}_{\mathrm{w}}\right)$, temperatura da atividade de água $\left[\mathrm{a}_{\mathrm{w}}\left({ }^{\circ} \mathrm{C}\right)\right]$, força mínima de cisalhamento (FMC), força média de cisalhamento (FPCIS), pico da força máxima de cisalhamento (PCIS), $\mathrm{pH}$ inicial e $\mathrm{pH}$ final de coxa, sobrecoxa e peito de frangos caipiras da linhagem Caipira Pesadão, aos 71 dias de idade, alimentados com diferentes níveis de feijão guandu (Cajanus cajan) cru moído nas dietas.

\begin{tabular}{|c|c|c|c|c|c|c|}
\hline \multirow[t]{2}{*}{ Variável } & \multicolumn{5}{|c|}{ Níveis de feijão guandu cru moído (\%) } & \multirow{2}{*}{$\begin{array}{l}\text { CV } \\
(\%)\end{array}$} \\
\hline & 0 & 5 & 10 & 15 & 20 & \\
\hline & \multicolumn{6}{|c|}{ Coxa } \\
\hline$a_{w}$ & 0,986 & 0,985 & 0,988 & 0,988 & 0,985 & 0,50 \\
\hline $\mathrm{a}_{\mathrm{w}}\left({ }^{\circ} \mathrm{C}\right)$ & 28,138 & 28,770 & 28,076 & 28,076 & 28,762 & 2,95 \\
\hline \multirow[t]{2}{*}{$\mathrm{pH}$ final } & 6,503 & 6,488 & 6,368 & 6,427 & 6,459 & 2,92 \\
\hline & \multicolumn{6}{|c|}{ Sobrecoxa } \\
\hline$a_{w}$ & 0,990 & 0,993 & 0,995 & 0,996 & 1,000 & 0,81 \\
\hline $\mathrm{a}_{\mathrm{w}}\left({ }^{\circ} \mathrm{C}\right)$ & 28,484 & 28,496 & 28,320 & 28,608 & 28,610 & 2,70 \\
\hline \multirow[t]{2}{*}{$\mathrm{pH}$ final } & 6,556 & 6,496 & 6,456 & 6,364 & 6,366 & 2,96 \\
\hline & \multicolumn{6}{|c|}{ Peito } \\
\hline$a_{w}$ & 0,985 & 0,983 & 0,985 & 0,982 & 0,983 & 0,57 \\
\hline $\mathrm{a}_{\mathrm{w}}\left({ }^{\circ} \mathrm{C}\right)$ & 28,174 & 28,650 & 27,996 & 28,378 & 28,824 & 3,03 \\
\hline FMC & 0,561 & 0,710 & 0,614 & 0,632 & 0,637 & 23,73 \\
\hline FPCIS & 4,768 & 4,714 & 4,040 & 4,400 & 4,311 & 16,29 \\
\hline PCIS & 5,213 & 5,654 & 4,750 & 5,194 & 5,327 & 13,14 \\
\hline $\mathrm{pH}$ inicial & 6,342 & 6,062 & 6,172 & 6,192 & 6,152 & 3,94 \\
\hline pH final & 6,224 & 6,016 & 6,110 & 6,030 & 6,142 & 2,77 \\
\hline
\end{tabular}

\section{Conclusão}

A substituição do farelo de soja pelo feijão guandu cru em rações para frangos caipiras, em até $15,45 \%$, não compromete o ganho de peso das aves, o rendimento de carcaça, o peso do pâncreas e a qualidade da carne.

\section{Agradecimentos}

À Fundação de Amparo à Pesquisa do Estado de Minas Gerais (Fapemig), pelo apoio financeiro.

\section{Referências}

AHMED, B.H.; ABDEL ATI, K.A.; ELAWAD, S.M. Effect of feeding different levels of soaked pigeon pea (Cajanus cajan) seeds on broilers chickens performance and profitability. Research Journal of Animal and Veterinary Sciences, v.1, p.1-4, 2006.

AMAEFULE, K.U.; UKPANAH, U.A.; IBOK, A.E. Performance of starter broilers fed raw pigeon pea [Cajanus cajan (L.) Millsp.] seed meal diets supplemented with lysine and or methionine. International Journal of Poultry Science, v.10, p.205-211, 2011. DOI: 10.3923/ijps.2011.205.211.

BRITO, C.O.; ALBINO, L.F.T.; ROSTAGNO, H.S.; GOMES, P.C.; DIONÍZIO, M.A.; CARVALHO, D.C.O. Adição de complexo multienzimático em dietas à base de soja extrusada e desempenho de pintos de corte. Revista Brasileira de Zootecnia, v.35, p.457461, 2006. DOI: 10.1590/S1516-35982006000200017.

CAMPELLO, C.C.; FIGUEIREDO, C.H.R. de; MONTENEGRO, R.C.; NOGUEIRA, G.C.; SAMPAIO, F.A.C.; CARDOSO, W.M.; SANTOS, M. do S.V. dos; SOUZA, F.M. de. Características de carcaça de frangos de corte alimentados com dietas contendo soja integral crua. Revista Ciência Animal, v.19, p.131-139, 2009.

CARRIJO, A.S.; FASCINA, V.B.; SOUZA, K.M.R. de; RIBEIRO, S. da S.; ALLAMAN, I.B.; GARCIA, A.M.L.; HIGA, J.A. Níveis de farelo da raiz integral de mandioca em dietas para fêmeas de frangos caipiras. Revista Brasileira de Saúde e Produção Animal, v.11, p.131-139, 2010.

HAJOS, G.; OSAGIE, A.U. Technical and biotechnological modifications of antinutritional factors in legume and oilseeds. In: MUSQUIZ, M.; HILL, G.D.; CUADRADO, C.; PEDROSA, M.M.; BURBANO, C. (Ed.). Recent advances of research in antinutritional factors in legume seeds and oilseeds. Wageningen: Wageningen Academic, 2004. p.293-305.

IORGYER, M.I.; ODOH, O.E.; IKONDO, N.D.; OKOH, J.J. The replacement value of pigeon pea (Cajanus Cajan) for maize on performance of broiler finishers. Patnsuk Journal, v.1, p.67-74, 2009.

LEITE, P.R. de S. da C.; MENDES, F.R.; PEREIRA, M.L.R.; LACERDA, M.J.R. Limitações da utilização da soja integral e farelo de soja na nutrição de frangos de corte. Enciclopédia Biosfera, v.8, p.1138-1157, 2012. 
MADEIRA, L.A.; SARTORI, J.R.; ARAUJO, P.C.A.; PIZZOLANTE, C.C.; SALDANHA, É.S.P.B.; PEZZATO, A.C. Avaliação do desempenho e do rendimento de carcaça de quatro linhagens de frangos de corte em dois sistemas de criação. Revista Brasileira de Zootecnia, v.39, p.2214-2221, 2010. DOI: 10.1590/ S1516-35982010001000017.

MATTERSON, L.D.; POTTER, L.M.; STUTZ, N.W.; SINGSEN, E.P. Metabolizable energy of feed ingredients for chickens. Storrs: University of Connecticut, 1965. 11p.

MIZUBUTI, I.Y.; FONSECA, N.A.N.; PINHEIRO, J.W.; MOTTER, A.A.; VAN DIJK, J.M.; GOIS, R.M.; ELEUTÉRIO, F.B. Efeito da utilização do feijão guandu cru moído (Cajanus cajan (L.) Millsp) sobre o desempenho de frangos de corte. Revista da Sociedade Brasileira de Zootecnia, v.24, p.590-598, 1995.

ONU, P.N.; OKONGWU, S.N. Performance characteristics and nutrient utilization of starter broilers fed raw and processed pigeon pea (Cajanus cajan) seed meal. International Journal of Poultry Science, v.5, p.693-697, 2006. DOI: 10.3923/ijps.2006.693.697.

RAMOS, E.M.; GOMIDE, L.A. de M. Avaliação da qualidade de carnes: fundamentos e tecnologias. Viçosa: Ed. da UFV, 2009. 599 p.

RODRIGUES, K.F.; RODRIGUES, P.B.; BRESSAN, M.C.; NAGATA, A.K.; SILVA, J.H.V. da; SILVA, E.L. da. Qualidade da carne de peito de frangos de corte recebendo rações com diferentes relações lisina digestível: proteína bruta. Revista Brasileira de Zootecnia, v.37, p.1023-1028, 2008. DOI: 10.1590/S151635982008000600011 .

ROSTAGNO, H.S. Tabelas brasileiras para aves e suínos: composição de alimentos e exigências nutricionais. 2.ed. Viçosa: Ed. da UFV, 2005. 141p.

SABADINI, E.; HUBINGER, M.D.; SOBRAL, P.J. do A.; CARVALHO JUNIOR, B.C. Alterações da atividade de água e da cor da carne no processo de elaboração da carne salgada desidratada. Ciência e Tecnologia de Alimentos, v.21, p.14-19, 2001. DOI: $10.1590 / \mathrm{S} 0101-20612001000100005$.

SAEED, M.S.; ABDEL ATI, K.A. Inclusion of pigeon pea (Cajanus cajan) seed on broiler chick's diet. Research Journal of Animal and Veterinary Sciences, v.2, p.1-4, 2007.

SAKOMURA, N.K.; ROSTAGNO, H.S. Métodos de pesquisa em nutrição de monogástricos. Jaboticabal: Funep, 2007. 283p.

SANTOS, A.L. dos; SAKOMURA, N.K.; FREITAS, E.R.; FORTES, C.M.L.S.; CARRILHO, E.N.V.M.; FERNANDES, J.B.K. Estudo do crescimento, desempenho, rendimento de carcaça e qualidade de carne de três linhagens de frango de corte. Revista Brasileira de Zootecnia, v.34, p.1589-1598, 2005. DOI: 10.1590/ S1516-35982005000500020.

SILVA, D.J.; QUEIROZ, A.C. Análise de alimentos: métodos químicos e biológicos. 3.ed. Viçosa: UFV, 2006. 235p.

VIEIRA, R.F.; VIEIRA, C.; VIEIRA, R.F. Leguminosas graníferas. Viçosa: Ed. da UFV, 2001. 206p.

Recebido em 14 de dezembro de 2013 e aprovado em 19 de agosto de 2014 